\title{
Comparison of the systemic effects of fluticasone propionate and budesonide given by dry powder inhaler in healthy and asthmatic subjects
}

\author{
T W Harrison, A Wisniewski, J Honour, A E Tattersfield
}

\begin{abstract}
Background-The potential for long term adverse effects from inhaled corticosteroids relates to their systemic absorption, usually assessed from proxy markers in short term studies. When fluticasone propionate and budesonide have been compared in this way the results have been inconsistent. To determine whether this is because of the subjects studied or the sensitivity of the systemic marker used, we have compared the effects of fluticasone propionate and budesonide in healthy and asthmatic subjects and investigated the effect of treatment on three systemic markers.

Methods-Forty six healthy subjects were randomised to receive inhaled fluticasone propionate $1500 \mu \mathrm{g} / \mathrm{day}$ (via an Accuhaler), budesonide $1600 \mu \mathrm{g} / \mathrm{day}$ (via a Turbuhaler), or placebo; 31 subjects with moderately severe asthma were randomised to receive the same doses of fluticasone propionate or budesonide but not placebo. Systemic effects in healthy and asthmatic subjects were compared after 7 days. Treatment was continued for another 21 days in the subjects with asthma when systemic effects and asthma control were assessed.
\end{abstract}

Results-At baseline healthy subjects had higher urinary levels of total cortisol metabolites (TCM) than subjects with asthma. After 7 days of treatment with fluticasone propionate urinary TCM levels in the healthy subjects were significantly lower than in the subjects with asthma (mean difference between groups $1663 \mu \mathrm{g} / \mathrm{day}, 95 \%$ CI 328 to 2938). This was not the case with budesonide, however, where urinary TCM levels in the healthy subjects remained above those in the asthmatic subjects (mean difference between groups $1210 \mu \mathrm{g} / \mathrm{day}, 95 \% \mathrm{CI}-484$ to 2904 ). Urinary TCM levels were considerably more sensitive to the effects of inhaled corticosteroids than morning serum cortisol or osteocalcin concentrations. Only budesonide reduced the serum level of osteocalcin.

Conclusions-When given by dry powder inhaler for 7 days, fluticasone propionate $1500 \mu \mathrm{g} / \mathrm{day}$ has a greater effect on the hypothalamic-pituitary-adrenal axis in healthy subjects than in subjects with asthma, but this is not the case for budesonide $1600 \mu \mathrm{g} / \mathrm{day}$. These findings, together with the differences in sensitivity between systemic markers, explain many of the discrepancies in the literature. (Thorax 2001;56:186-191)

Keywords: inhaled corticosteroids; asthma; systemic effects

Inhaled corticosteroids are highly effective and widely prescribed for asthma. When given in low doses, systemic effects are not apparent but the use of higher doses has been associated with skin bruising, ${ }^{1}$ cataracts, ${ }^{2}$ loss of glycaemic control, ${ }^{3}$ and a reduction in bone mineral density. ${ }^{4}$ The currently available inhaled corticosteroids have very different pharmacokinetic properties and this may lead to important differences in the balance between efficacy and systemic activity. Since clinical adverse effects such as osteoporosis are difficult to measure, various proxy measures have been used to assess systemic activity. Many studies have compared the available inhaled corticosteroids but there has been considerable inconsistency in their results, particularly with respect to the systemic effects of fluticasone propionate and budesonide.

Short term treatment with fluticasone propionate in healthy subjects or subjects with mild asthma has been associated with considerable suppression of the hypothalamic-pituitaryadrenal (HPA) axis and in comparative studies it has 2-5 times the systemic potency of budesonide..$^{5-9}$ However, when subjects with more severe asthma have been given similar doses of fluticasone propionate, the systemic effects have been considerably less ${ }^{10-12}$ and a meta-analysis of seven studies in subjects with asthma concluded that fluticasone propionate has a more favourable ratio of efficacy to systemic activity than budesonide. ${ }^{13}$

The reasons for these large discrepancies are not clear. There are marked differences in methodology between studies including the use of healthy subjects or subjects with asthma, the choice of systemic marker, and the study design. To explore these variables we compared the systemic activity of fluticasone propionate and budesonide in steroid naive healthy subjects and in patients with moderately severe asthma. Urinary levels of total cortisol metabolites (TCM) were used as a sensitive marker of inhaled corticosteroid absorption ${ }^{14}$ and the sensitivity of urinary TCM was compared with morning serum cortisol and osteocalcin levels. 
Methods

SUBJECTS

All subjects were aged $16-50$ years and were current non-smokers with a smoking history of less than 10 pack years. The healthy subjects had no past or present history of asthma. The inclusion criteria for the subjects with asthma were: forced expiratory volume in one second $\left(\mathrm{FEV}_{1}\right)$ of less than $75 \%$ predicted; daily symptoms requiring a short acting $\beta$ agonist despite taking a high dose inhaled corticosteroid (beclomethasone dipropionate 1000-2000 $\mu \mathrm{g} /$ day, budesonide 1000-1600 $\mu \mathrm{g} /$ day, or fluticasone propionate $500-1000 \mu \mathrm{g} /$ day); diurnal variation in peak expiratory flow (PEF) of $15 \%$ on two days of the run in period or $15 \%$ reversibility to $200 \mu \mathrm{g}$ inhaled salbutamol. Asthma had to be stable on entry with no change in asthma treatment in the 8 weeks prior to the study.

Subjects were excluded from both groups if they had another respiratory diagnosis or were taking oral, topical, or nasal corticosteroids or a leukotriene antagonist.

All subjects gave written informed consent to the study which was approved by the Nottingham City Hospital ethics committee.

\section{MEASUREMENTS}

$\mathrm{FEV}_{1}$ was measured by dry bellows spirometer (Vitalograph, Vitalograph Ltd, Bucks, UK) as the higher of two measurements within $100 \mathrm{ml}$ and PEF as the best of three readings using a mini-Wright peak flow meter (Clement Clarke International Ltd, Essex, UK). PEF, $\beta$ agonist use, and symptom scores (from $0=$ no symptoms to $4=$ severe symptoms) were recorded twice daily in diary cards throughout the study. Bronchial responsiveness to methacholine was measured using a modification of the method of Yan et $a l^{15}$ as described previously. ${ }^{16}$ The provocative dose of methacholine required to cause a $20 \%$ fall in $\mathrm{FEV}_{1}$ $\left(\mathrm{PD}_{20}\right)$ was calculated by linear interpolation of the last two readings on the log dose response plot. Asthmatic subjects were instructed to withhold short acting and long acting bronchodilators for 6 and 12 hours, respectively, before the study visits which were at the same time of day.

The cortisol and cortisone metabolites tetrahydrocortisone, tetrahydrocortisol, allotetrahydrocortisol, $\alpha$-cortolone, $\beta$-cortol, $\beta$-cortolone, and $\alpha$-cortol were analysed by gas chromotography on a sample from the 24 hour urine collection and the individual results were summed to give the urinary TCM excretion (intra-assay and inter-assay coefficient of variation (CV) $7.6 \%$ and $10.1 \%$, respectively). The mean intra-assay and inter-assay $\mathrm{CV}$ for serum cortisol (Chiron Diagnostics ACS; Centaur Automated Chemiluminescence System, MA, USA) and osteocalcin (Human Osteocalcin IRMA Kit; Immunotopics, CA, USA) were $3.2 \%$ and $8.2 \%$, and $4.6 \%$ and $6.1 \%$, respectively. Plasma concentrations of fluticasone propionate and budesonide were measured by automated solid phase extraction followed by liquid chromotography tandem mass spectrometry (GlaxoWellcome, Ware, UK) with an intra-assay and inter-assay $\mathrm{CV}$ of $5.3 \%$ and $3.3 \%$ for fluticasone propionate and $9.5 \%$ and $11.7 \%$ for budesonide. The lower limit of quantification for the assays were $20 \mathrm{pg} / \mathrm{ml}$ for fluticasone propionate and $50 \mathrm{pg} / \mathrm{ml}$ for budesonide.

PROTOCOL

This was a double blind, double dummy, parallel group study performed in 31 subjects with moderately severe asthma and 46 healthy subjects. Asthmatic subjects had a 1 week run in period to ensure they fulfilled the inclusion criteria. $\mathrm{FEV}_{1}$ and reversibility to salbutamol $200 \mu \mathrm{g}$ were carried out at the beginning of the run in period and methacholine $\mathrm{PD}_{20}$ was measured at the end. Subjects fulfilling the inclusion criteria were randomised using computer generated random number tables to receive fluticasone propionate $1500 \mu \mathrm{g}$ /day or budesonide $1600 \mu \mathrm{g} /$ day for 28 days instead of their usual inhaled corticosteroid. Healthy subjects were randomised to receive fluticasone propionate $1500 \mu \mathrm{g} /$ day, budesonide $1600 \mu \mathrm{g} /$ day, or placebo for 7 days. Fluticasone propionate and budesonide were administered twice daily via dry powder inhalers, Accuhaler (Allen \& Hanburys Ltd, Middlesex, UK) and Turbuhaler (Astra Pharmaceuticals Ltd, Hertfordshire, UK), respectively.

All subjects were seen at $08.00( \pm 1)$ hours on the first and eighth day when they delivered the urine collected over the previous 24 hours. A venous blood sample was taken for measurement of cortisol, osteocalcin, and corticosteroid levels and spirometric tests were performed on the subjects with asthma. The asthmatic subjects made a further visit after 4 weeks of treatment when these measures and the methacholine challenge test were repeated.

The primary end point was the difference in absolute mean urinary TCM levels between the asthmatic and healthy subjects after 7 days of treatment with fluticasone propionate and budesonide. Fifteen subjects in each group provided $80 \%$ power to detect a difference of at least $20 \%$ in urinary TCM levels between asthmatic and control subjects (J Honour, unpublished data). Secondary end points were a comparison of the effects of the inhaled corticosteroids on serum cortisol and osteocalcin levels in relation to urinary TCM and the effects of fluticasone propionate and budesonide on PEF, $\mathrm{FEV}_{1}$, symptom scores, and bronchial reactivity to methacholine.

ANALYSIS OF DATA

We predicted that baseline urinary TCM levels would be lower in the asthmatic patients because of previous inhaled steroid use so, for the primary comparison between healthy and asthmatic subjects, we compared absolute urinary TCM levels at day 7 (rather than change from baseline). For comparison of the effects of fluticasone propionate and budesonide on the three systemic markers within the healthy subjects and subjects with asthma we compared change from baseline with adjustment for differences in baseline. All comparisons were performed using analysis of covariance with 
Table 1 Age, FEV , peak flow, methacholine $\mathrm{PD}_{20}$, symptom score, and $\beta$ agonist use in 31 asthmatic subjects at baseline and week 4

\begin{tabular}{|c|c|c|c|c|c|c|}
\hline & \multicolumn{3}{|c|}{ Fluticasone propionate } & \multicolumn{3}{|l|}{ Budesonide } \\
\hline & Baseline & Week 4 & Change $(95 \% \mathrm{CI})$ & Baseline & Week 4 & Change $(95 \%$ CI) \\
\hline Mean (SD) age (years) & $43(8)$ & & & $42(8)$ & & \\
\hline Mean (SD) $\mathrm{FEV}_{1}(1)$ & $1.86(0.71)$ & $2.17(0.78)$ & $0.31(0.08 \text { to } 0.53)^{\star}$ & $2.12(0.67)$ & $2.27(0.59)$ & $0.15(-0.08$ to 0.3$)$ \\
\hline Geometric mean $(\log \mathrm{SD}) \mathrm{PD}_{20}(\mu \mathrm{mol}) \ddagger$ & $0.32(0.2)$ & $0.81(0.2)$ & 1.9 DD† & $0.36(0.2)$ & $0.51(0.2)$ & $0.5 \mathrm{DD}+$ \\
\hline Mean (SD) morning PEF $(1 / \mathrm{min})$ & $317(105)$ & $358(107)$ & $41(-3$ to 85$)$ & $348(92)$ & $376(89)$ & $28(11 \text { to } 45)^{\star}$ \\
\hline Mean (SD) evening PEF ( $1 / \mathrm{min})$ & $332(100)$ & $359(93)$ & $27(6 \text { to } 48)^{\star}$ & $357(89)$ & $375(89)$ & $18(-5$ to 43$)$ \\
\hline Median (range) daily symptom score & $2.25(1$ to 4$)$ & $1(0$ to 4$)$ & -1.25 & $2(1$ to 6$)$ & $1(0$ to 4$)$ & $-1^{\star}$ \\
\hline Median (range) daily $\beta$ agonist use (puffs/day) & $6(2.5$ to 12$)$ & $4(0$ to 10$)$ & $-2^{\star}$ & $5(2$ to 12$)$ & $2(0$ to 14$)$ & $-3^{\star}$ \\
\hline
\end{tabular}

$\mathrm{FEV}_{1}=$ forced expiratory volume in one second; $\mathrm{PEF}=$ peak expiratory flow; $\mathrm{DD}=$ doubling doses.

${ }^{\star} \mathrm{p}<0.05$ between baseline and week 4 .

$\mathrm{tp}<0.05$ between fluticasone propionate and budesonide.

$\ddagger \mathrm{PD}_{20}$ methacholine was only performed in 10 subjects in each group.

adjustment for sex. The data approximated to a normal distribution except for absolute serum cortisol values which were log transformed before analysis.

Since many of the fluticasone propionate and budesonide plasma levels were below the limit of quantification, the results are expressed as median values and the proportion of subjects with detectable levels were compared between asthmatic and control subjects by $\chi^{2}$ test. The Student's $t$ test was used to compare $\mathrm{FEV}_{1}$, morning and evening peak flow, and log transformed $\mathrm{PD}_{20}$ methacholine, and nonparametric tests were used for symptom score and $\beta$ agonist inhalations. Mean values with $95 \%$ confidence intervals (CI) are given where relevant.

\section{Results}

Of the 31 patients with asthma (mean age 42 years), one withdrew from the fluticasone propionate group during week 3 following an exacerbation of asthma, but data up to day 8 are included in the analysis. Sixteen subjects (11 women) received fluticasone propionate and 15 (10 women) received budesonide. The two groups were of similar age but the fluticasone propionate group had slightly lower measures of lung function than the budesonide group (mean $\mathrm{FEV}_{1} 56 \%$ and $64 \%$ predicted, respectively) and higher symptom scores and $\beta$ agonist use as shown in table 1.

Forty six healthy subjects (mean age 34 years) completed the study but data from one subject taking fluticasone propionate were excluded before unblinding the data due to incorrect use of study medication. Data were therefore available for 15 subjects per group of whom 10,11, and eight were women in the fluticasone propionate, budesonide, and placebo groups, respectively.

EFFECTS OF 7 DAYS INHALED CORTICOSTEROID ON URINARY TCM LEVELS

Fluticasone propionate

The healthy subjects had higher mean urinary TCM levels at baseline than the subjects with asthma. After 7 days of treatment with fluticasone propionate, however, mean urinary TCM values were lower in the healthy subjects than in the asthmatic subjects, the mean difference between groups being $1633 \mu \mathrm{g} /$ day $(95 \%$ CI 328 to 2938 , $p=0.02$; fig 1 ). Six healthy and two asthmatic subjects had urinary TCM values below the lower limit of normal after 7

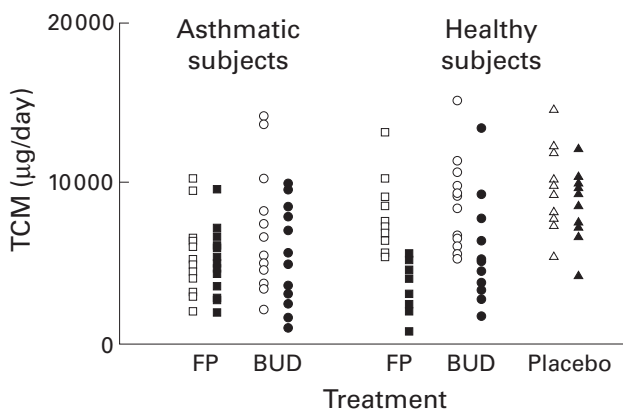

Figure 1 Individual urinary total cortisol metabolite levels (TCM) at baseline (open symbols) and after 7 days of treatment (solid symbols) with fluticasone propionate (FP, $1500 \mu \mathrm{g} /$ day), budesonide (BUD, $1600 \mu \mathrm{g} /$ day) or placebo (healthy subjects only). Data for subjects with asthma are on the left and for healthy subjects on the right.

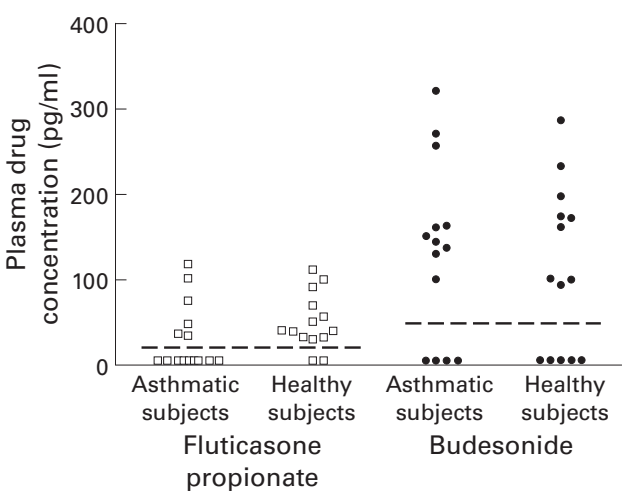

Figure 2 Individual morning plasma drug concentrations in subjects with asthma and healthy subjects. The broken line indicates the limit of quantification of the assay.

days of treatment compared with only two asthmatic subjects at baseline.

Two healthy and nine asthmatic subjects had morning fluticasone propionate plasma levels below the limit of detection on day $8(\mathrm{p}=0.02$, $\chi^{2}$ test, fig 2); median plasma levels were $39 \mathrm{pg} /$ $\mathrm{ml}$ and $0 \mathrm{pg} / \mathrm{ml}$ in the healthy and asthmatic subjects, respectively.

Budesonide

Mean urinary TCM values were higher in the healthy subjects than in the asthmatic subjects at baseline. They remained higher after 7 days of treatment with budesonide although the difference between healthy and asthmatic subjects was not significant, the mean difference being $1210 \mu \mathrm{g} /$ day $(95 \%$ CI 484 to 2904 , p=0.2; fig 1). Urinary TCM levels were below the lower limit of normal in two asthmatic subjects after 7 days of treatment compared with one at 
Table 2. Mean baseline values for three systemic markers of inhaled corticosteroid absorption in asthmatic and healthy subjects

\begin{tabular}{llllll}
\hline & $\begin{array}{l}\text { Asthmatic } \\
(n=31)\end{array}$ & $\begin{array}{l}\text { Healthy } \\
(n=45)\end{array}$ & $\begin{array}{l}\text { Mean difference } \\
(95 \% \mathrm{CI})\end{array}$ & $\begin{array}{l}\text { Ratio of geometric } \\
\text { means (95\% CI) }\end{array}$ & p value \\
\hline $\begin{array}{l}\text { Urinary total } \\
\text { cortisol } \\
\text { metabolites } \\
(\mu \mathrm{g} / \text { day) }\end{array}$ & 5897 & 8468 & $\begin{array}{l}2571(1237 \text { to } \\
3905)\end{array}$ & - & $<0.001$ \\
$\begin{array}{c}\text { Serum osteocalcin } \\
(\mathrm{ng} / \mathrm{ml})\end{array}$ & 4.2 & 5.7 & $\begin{array}{l}1.5(0.87 \text { to } \\
2.22)\end{array}$ & - & $<0.001$ \\
$\begin{array}{c}\text { Serum cortisol } \\
(\mathrm{nmol} / \mathrm{l})\end{array}$ & 449 & 537 & - & $1.19(1$ to 1.43$)$ & 0.05 \\
\hline
\end{tabular}

${ }^{\star}$ Geometric mean values.

baseline and were normal in all the healthy subjects at both time points.

Five healthy and four asthmatic subjects had morning budesonide plasma levels below the limit of quantification on day $8(\mathrm{p}=0.4$, fig 2$)$; median plasma levels were $109 \mathrm{pg} / \mathrm{ml}$ and $90 \mathrm{pg} / \mathrm{ml}$ in the healthy and asthmatic subjects, respectively.

COMPARISON OF THE THREE SYSTEMIC MARKERS OF INHALED CORTICOSTEROID ABSORPTION The asthmatic subjects had lower mean baseline values than the healthy subjects for all three systemic markers (table 2). The size of the difference varied, being greatest for urinary TCM levels (30\%), followed by serum osteocalcin $(26 \%)$ and serum cortisol levels $(17 \%)$. Treatment with inhaled corticosteroid (fluticasone propionate or budesonide) for 7 days in healthy subjects produced a marked reduction in urinary TCM levels (49\%) and smaller reductions in serum cortisol $(8 \%)$ and osteocalcin levels $(5 \%)$.

COMPARISON OF INHALED FLUTICASONE

PROPIONATE AND BUDESONIDE

Systemic effects

In the healthy subjects fluticasone propionate produced a greater reduction in urinary TCM levels and in the serum cortisol concentration than budesonide but the differences between treatments were not significant (fig 3). The mean difference between fluticasone propionate and budesonide was $1200 \mu \mathrm{g} /$ day for urinary TCM $(95 \% \mathrm{CI}-169$ to $2568, \mathrm{p}=0.08)$ and $74 \mathrm{nmol} / 1$ for serum cortisol levels $(95 \%$ CI -45 to $193, p=0.1)$. The serum osteocalcin concentration was reduced by budesonide but not by fluticasone propionate, the mean difference being $0.8 \mathrm{ng} / \mathrm{ml}$ (95\% CI 0.02 to 1.6 , $\mathrm{p}=0.04$ ).

In the asthmatic subjects there were no significant differences between the effects of fluticasone propionate and budesonide on urinary TCM or serum cortisol levels after 7 or 28 days of treatment. The serum osteocalcin concentration was again reduced by budesonide but not by fluticasone propionate, the mean differences being $0.7 \mathrm{ng} / \mathrm{ml}$ (95\% CI 0.3 to 1.2 , $\mathrm{p}=0.002)$ after 7 days and $0.8 \mathrm{ng} / \mathrm{ml}(95 \%$ CI 0.2 to $1.6, \mathrm{p}=0.01$ ) after 28 days.

\section{Asthma control}

Lung function and $\mathrm{PD}_{20}$ methacholine increased and $\beta$ agonist use fell during the 28 days treatment with both fluticasone propionate and budesonide (table 1). The changes

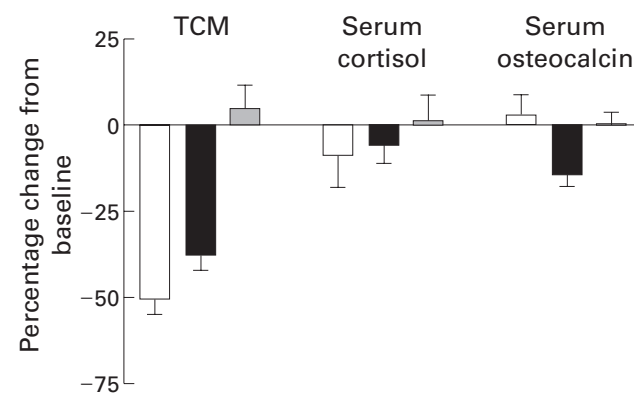

Figure 3 Mean (SE) change from baseline for three systemic markers following inhaled fluticasone propionate (open bars), budesonide (solid bars), and placebo (shaded bars) in healthy subjects. TCM = urinary total cortisol metabolites.

were slightly larger for fluticasone propionate but the only significant difference between treatments was for methacholine $\mathrm{PD}_{20}$ which increased by 1.9 doubling doses following fluticasone propionate compared with 0.5 doubling doses after budesonide (difference in doubling doses $1.44 ; 95 \%$ CI 0.13 to 2.76 , $\mathrm{p}=0.03)$.

\section{Discussion}

This study has produced several interesting findings that merit discussion and which together provide an explanation for much of the discrepancy between previous studies comparing the systemic activity of fluticasone propionate and budesonide. Firstly, healthy subjects had higher urinary TCM levels at baseline than the asthmatic subjects but lower levels after 7 days of treatment with fluticasone propionate. After 7 days of treatment with budesonide, however, urinary TCM levels remained above those in the asthmatic subjects. Secondly, the study highlights the differences in the sensitivity of markers used to assess systemic activity of inhaled corticosteroids, with urinary TCM being considerably more sensitive than morning serum cortisol or osteocalcin concentrations. Finally, our study raises the possibility that the relative effects of fluticasone propionate and budesonide on the HPA axis and bone metabolism may differ.

The large number of studies that have assessed the systemic activity of inhaled corticosteroids can be divided broadly into two main groups. One group has looked at the short term effect of different doses of inhaled corticosteroids under carefully controlled conditions in a relatively small number of healthy subjects or patients with very mild stable asthma. These studies have shown considerable suppression of the HPA axis, particularly following inhalation of high doses of fluticasone propionate, and they suggest that fluticasone propionate is $2-5$ times more potent than budesonide on the HPA axis. ${ }^{5-9}$

The other type of study has looked at larger numbers of patients with more severe asthma, usually in a multicentre setting and usually with only one dose of each drug. ${ }^{10-12}$ These studies have shown considerably less systemic activity from high doses of fluticasone propionate, and a meta-analysis of seven studies comparing fluticasone propionate and budesonide 
in subjects with asthma concluded that fluticasone propionate has the more favourable ratio of efficacy to systemic activity. ${ }^{13}$

Possible reasons for the conflicting results between the two types of study include the choice of subjects, choice of systemic marker, and the study design. The main aim of our study was to compare the systemic activity of fluticasone propionate and budesonide between healthy subjects and subjects with asthma while keeping the other variables constant. We selected asthmatic subjects for whom the relatively high doses of inhaled corticosteroid under study were broadly appropriate. We chose to give approximately equal doses of fluticasone propionate and budesonide rather than make assumptions about their relative potency when given by dry powder inhalers. Having equipotent doses was not essential since our main analysis was a between group comparison for each drug. Although the changes in lung function and symptoms in our study were small and did not differ between the two drugs, the greater reduction in bronchial reactivity with fluticasone propionate suggests that fluticasone propionate $1500 \mu \mathrm{g} /$ day via the Accuhaler may be more effective than budesonide $1600 \mu \mathrm{g} /$ day via the Turbuhaler.

SYSTEMIC EFFECTS OF FLUTICASONE PROPIONATE AND BUDESONIDE IN HEALTHY AND ASTHMATIC SUBJECTS

Urinary TCM levels were lower in healthy subjects than in asthmatic subjects after 7 days of treatment with fluticasone propionate, despite higher levels at baseline. This is probably due to greater systemic availability of fluticasone propionate in healthy subjects than in asthmatic subjects as seen in a recent pharmacokinetic study of fluticasone propionate. ${ }^{17}$ Such a mechanism would fit with the fluticasone propionate plasma levels in our study and could explain the strong correlation between the systemic activity of fluticasone propionate and $\mathrm{FEV}_{1}$ in asthmatic subjects in another study. ${ }^{18}$

We found no differences in urinary TCM levels and budesonide plasma levels between healthy and asthmatic subjects after treatment with budesonide, however. Why the absorption of fluticasone propionate, but not budesonide, should be reduced in subjects with asthma is uncertain, but it may be that the delivery device or absorption of fluticasone propionate is more sensitive to lung function or the presence of asthma than budesonide. We gave both drugs by their respective dry powder inhalers but, since similar differences between healthy and asthmatic subjects were seen when fluticasone propionate was given via a metered dose inhaler with a spacer, ${ }^{17}$ the differences probably relate more to the drug than to the delivery device.

Great care was taken to ensure inhaler technique was the same in both groups and that subjects complied with the study medication and performed accurate 24 hour urine collections. There were some differences in age and body mass index between the healthy subjects and subjects with asthma but fitting age, body mass index, or the difference in creatinine between the two urine collections into the statistical model did not alter our findings.

\section{CHOICE OF SYSTEMIC MARKER}

Urinary TCM measurement was more sensitive to the effects of inhaled corticosteroids than morning serum cortisol or osteocalcin concentrations. Others have suggested that a single morning cortisol level measurement is insensitive to the effects of inhaled corticosteroids, ${ }^{1920}$ although some studies have reported reductions in morning serum cortisol levels of approximately $90 \%$ with fluticasone propionate. ${ }^{67}$ The main differences between studies that show a large or small effect on morning serum cortisol levels appears to be the timing of the sample and whether or not subjects were admitted overnight. We chose to sample blood 1 hour either side of 08.00 hours to replicate the methodology of multicentre clinical trials. The relatively small effect of inhaled corticosteroids on morning cortisol levels measured under these conditions demonstrates that multicentre clinical trials could inappropriately conclude that two inhaled corticosteroids were equivalent.

\section{RELATIVE EFFECTS OF FLUTICASONE PROPIONATE} AND BUDESONIDE ON SYSTEMIC MARKERS Fluticasone propionate had a greater effect on the two markers of the HPA axis than budesonide, although neither difference was significant. Only budesonide reduced the serum osteocalcin concentration, however, and the effect of budesonide was significantly greater than that of fluticasone propionate in both the healthy and asthmatic subjects. We are unaware of any previous direct comparisons of the two drugs on serum osteocalcin levels, but a reduction in osteocalcin has been seen with budesonide at doses of $800 \mu \mathrm{g} /$ day or more $\mathrm{e}^{21-23}$ and with fluticasone propionate at a dose $2000 \mu \mathrm{g} /$ day but not $1000 \mu \mathrm{g} /$ day. ${ }^{24}$ Our unexpected finding raises the possibility that fluticasone propionate and budesonide have differential effects on the HPA axis and bone metabolism. Such disassociation of the effects of corticosteroids could be due to differences in the intracellular concentration of the two drugs in different tissues or differences in their effects on genomic and non-genomic mechanisms of action, as discussed recently. ${ }^{25}$ Confirmation of this potentially important finding is required.

This study therefore shows that the systemic activity of fluticasone propionate $1500 \mu \mathrm{g}$ /day given via an Accuhaler is greater in healthy subjects than in subjects with moderately severe asthma, but the same difference is not seen with budesonide $1600 \mu \mathrm{g} /$ day given via a Turbuhaler. It confirms that there are important differences in the sensitivity of different markers of inhaled corticosteroid absorption and that morning serum cortisol concentrations in ambulant patients are relatively insensitive to the effects of inhaled corticosteroids. Finally, it raises the possibility of some dissociation of the effects of fluticasone propionate and budesonide on the HPA axis and bone metabolism. Together these findings 
explain many of the discrepancies in the literature and suggest that extrapolation of findings from healthy subjects may be misleading since they may overestimate the systemic response to some, but not all, inhaled corticosteroids.

We thank S Pacey (Pharmacy) for supplying the treatments and randomisation schedule, I Fowler (Department of Biochemistry) for performing the cortisol and osteocalcin assays, and $S$ Lewis (statistician) for help with the analysis (all Nottingham City Hospital). We also thank K Crescenzi, R Pearson, and S Callejas at GlaxoWellcome for advice and for performing the Callejas at GlaxoWellcome for advice and for
fluticasone propionate and budesonide assays.

Funding: The study was supported by a grant from GlaxoWellcome.

1 Pauwels RA, Löfdal C-G, Laitinen LA, et al. Long-term treatment with inhaled budesonide in persons with mild chronic obstructive pulmonary disease who continue to chronic obstructive pulmonary disease
smoke. N Engl f Med 1999;340:1948-53.

2 Cumming RG, Mitchel P, Leeder S. Use of inhaled corticocumming RG, Mitchel P, Leeder S. Use of inhaled cortico$8-14$.

3 Faul JL, Tormey W, Burke C. High dose inhaled corticosteroids and dose dependent loss of diabetic control. BMF 1999;317:1491.

4 Wong CA, Walsh LJ, Smith CJP, et al. Inhaled corticosteroid use and bone-mineral density in patients with asthma. Lan cet 2000;355:1399-403.

5 Clark D J, Grove A, Cargill RI, et al. Comparative adrena suppression with inhaled budesonide and fluticasone propionate in adult asthmatic patients. Thorax 1996;51: 262-6.

6 Donnelly R, Williams KM, Baker AB, et al. Effects of budesonide and fluticasone on 24-hour plasma cortisol. Am 7 Respir Crit Care Med 1997;156:1746-51.

7 Boorsma M, Anderson N, Larsson P, et al. Assessment of the relative systemic potency of inhaled fluticasone and budesonide. Eur Respir 7 1996;9:1427-32.

8 Clark DJ, Lipworth BJ. Adrenal suppression with chronic dosing of fluticasone propionate compared with budesodosing of fluticasone propionate compared with budeso

9 Grahnén A, Jansson B, Brundin RM, et al. A dose-response Grahnen A, Jansson B, Brundin RM, et al. A dose-response
study comparing suppression of plasma cortisol induced by fluticasone propionate from Diskhaler and budesonice from Turbuhaler. Eur f Clin Pharmacol 1997;52:261-7.

10 Barnes NC, Marone G, Di Maria GU, et al. A comparison of fluticasone propionate, $1 \mathrm{mg}$ daily, with beclomethasone dipropionate, $2 \mathrm{mg}$ daily, in the treatment of severe asthma. Eur Respir F 1993;6:877-84.

11 Ayres JG, Bateman ED, Lundback B, et al. High dose fluticasone propionate, $1 \mathrm{mg}$ daily, versus fluticasone propionate, $2 \mathrm{mg}$ daily, or budesonide $1.6 \mathrm{mg}$ daily, in patients with chronic severe asthma. Eur Respir f 1995;8:579-86.

12 Fabbri L, Burge PS, Croonenborgh L, et al. Comparison of fluticasone propionate with beclomethasone dipropionate in moderate to severe asthma treated for one year. Thorax 1993;48:817-23.

13 Barnes NC, Hallett C, Harris TA. Clinical experience with fluticasone propionate in asthma: a meta-analysis of efficacy and systemic activity compared with budesonide and beclomethasone dipropionate at half the microgram dose or less. Respir Med 1998;92:95-104.

14 Priftis K, Milner AD, Conway E, et al. Adrenal function in asthma. Arch Dis Child 1990;65:838-40

15 Yan K, Salome C, Woolcock AJ. Rapid method for measurement of bronchial responsiveness. Thorax 1983;38:760-5.

16 Harrison TW, Oborne J, Wilding PJ, et al. Randomised placebo controlled trial of $\beta$-agonist dose reduction in asthma. Thorax 1999;54:98-102.

17 Brutsche $\mathrm{MH}$, Carlen Brutsche I, Munavvar M, et al. Pharmacokinetics and systemic effects of inhaled fluticasone propionate are different in asthmatic and normal volunteers. Lancet 2000;356:556-61

18 Weiner P, Berar-Yanay N, Davidovich A, et al. Nocturnal cortisol secretion in asthmatic patients after inhalation of fluticasone propionate. Chest 1999;116:931-4.

19 Barnes PJ, Pedersen S. Efficacy and safety of inhaled corticosteroids in asthma. Am Rev Respir Dis 1993;148:S126.

20 Geddes DM. Inhaled corticosteroids: benefits and risks. Thorax 1992;47:404-7.

21 Wilson AM, Brewster HJA, Lipworth BJ. Dose-response comparison of systemic bioactivity with inhaled budesonide and triamcinolone acetonide in asthmatic adults. 7 Allergy Clin Immunol 1998;102:751-6.

22 Hodsman AB, Toogood JH, Jennings B, et al. Differential effects of inhaled budesonide and oral prednisolone on serum osteocalcin. F Clin Endocrinol Metab 1991;72:53040

23 Toogood JH, Jennings B, Hodsman AB, et al. Effects of dose and dosing schedule of inhaled budesonide on bone turnover. F Allergy Clin Immunol 1991;88:572-80.

24 Wilson AW, Lipworth BJ. Short-term dose-response relationship for the relative systemic effects of oral prednisolone and inhaled fluticasone in asthmatic adults. $\mathrm{Br} 7$ Clin Pharmacol 1999;48:579-85.

25 Newton R. Molecular mechanisms of glucocorticoid action: what is important? Thorax 2000;55:603-13. 